UDC 341

LBC 67.412

\title{
THE IMPACT OF THE WTO LAW ON FORMING ANTIDUMPING LEGISLATION OF THE REPUBLIC OF TAJIKISTAN
}

\author{
Andrey M. Nikolaev \\ RUDN University, Moscow, Russian Federation \\ Umed M. Mamadamonov \\ Russian-Tajik (Slavic) University, Dushanbe, Tajikistan
}

\begin{abstract}
Introduction: the authors examine the impact of the World Trade Organization (WTO) law on the formation of the antidumping legislation of the Republic of Tajikistan. The formation of the antidumping legislation of the WTO members and the adoption of antidumping rules under the WTO law are considered. Methods: the methodological framework includes the historical, formal and logical, comparative law methods of cognition. Results: based on the study of forming the antidumping laws of the WTO members and the WTO law there can be concluded about the need to change the antidumping legislation of the Republic of Tajikistan for a more effective application of the antidumping measures to protect the national interest. Conclusions: as a result of the study the authors suggest adopting a special law in Tajikistan in the field of antidumping, countervailing duties and remedies, which would be fully consistent with the WTO law and help to further improve the antidumping legislation of the Republic of Tajikistan.
\end{abstract}

Key words: dumping, antidumping, remedies, legislation, the WTO law.

УДК 341

ББК 67.412

\section{ВОЗДЕЙСТВИЕ ПРАВА ВСЕМИРНОЙ ТОРГОВОЙ ОРГАНИЗАЦИИ НА СТАНОВЛЕНИЕ АНТИДЕМПИНГОВОГО ЗАКОНОДАТЕЛЬСТВА РЕСПУБЛИКИ ТАДЖИКИСТАН \\ Андрей Михайлович Николаев}

Российский университет дружбы народов, г. Москва, Российская Федерация

Умед Мулкамонович Мамадамонов

Российско-Таджикский (славянский) университет, г. Душанбе, Республика Таджикистан

Введение: авторы исследуют воздействие права Всемирной торговой организации (ВТО) на становление антидемпингового законодательства Республики Таджикистан. Рассматривается становление антидемпингового законодательства членов ВТО и принятие антидемпинговых норм в рамках права ВТО. Методы: методологическую основу данного исследования составили исторический, формально-логический, сравнительно-правовой методы познания. Результаты: на основе изучения становления антидемпингового законодательства членов ВТО и права ВТО можно сделать вывод о необходимости изменения антидемпингового законодательства Республики Таджикистан для более эффективного применения антидемпинговых мер для защиты национального интереса. Выводы: в результате исследования предложено принятие отдельного закона в Таджикистане в области антидемпинга, компенсационных пошлин и защитных мер, которые бы полностью соответствовали праву ВТО и способствовали дальнейшему совершенствованию антидемпингового законодательства Республики Таджикистан.

Ключевые слова: демпинг, антидемпинговые меры, защитные меры, законодательство, право ВТО. 


\section{МЕЖДУНАРОДНОЕ ПРАВО И СРАВНИТЕЛЬНОЕ ПРАВОВЕДЕНИЕ}

\section{Введение}

В настоящее время ВТО можно характеризовать как один из основных институтов, обеспечивающих организационно-правовую основу развития международной торговли. Вступление в ВТО - продолжительный и благоприятный процесс для экономики и законодательства государства. Республика Таджикистан (далее - РТ), как полноправный субъект международного права, с первых дней своего становления подчеркнула свою приверженность общепризнанным принципам и нормам международного права и взяла курс на интеграцию в мировое сообщество. Вступление Республики Таджикистан в ВТО стало одним из основополагающих факторов ее интеграции в мировую экономику.

\section{Антидемпинговые меры в праве ВТО}

Процесс интеграции РТ в мировое хозяйство должен проходить без ущерба для государственного суверенитета. Для этого необходимо придерживаться такой государственной политики, которая заключается в целенаправленном развитии народного хозяйства страны по пути модернизации.

При этом, как обоснованно отмечает О.М. Мещерякова, следует принимать во внимание и тот факт, что членство в интеграционных объединениях осложняет задачи, которые приходится решать государствам, присоединяющимся к ВТО. Данный процесс оказывает влияние на исполнение международных правил и обязательств в сфере торговли по отношению к интеграционным объединениям и их государствам-членам, в которые вступающее в ВТО государство не входит [6, с. 86].

Как отметил генеральный директор ВТО Паскаль Лами, вступив в организацию, Таджикистан сможет лучше использовать торговлю в качестве инструмента для своего развития и роста, как это сделали другие страны. Последовательное отстаивание Таджикистаном своих национальных интересов через многочисленные международные организации, безусловно, будет способствовать укреплению стабильности и безопасности как внутри страны, так и во всем международном сообществе, содействовать дальнейшему расши- рению взаимодействия с другими государствами [5, с. 23].

Одним из эффективных инструментов, которым сможет в дальнейшем воспользоваться РТ для отстаивания национальных интересов, является Орган по разрешению споров (далее - ОРС) ВТО. На сегодняшний день ОРС доказал свою эффективность и уникальность в разрешении межгосударственных торговых споров.

Антидемпинговые меры, будучи исключением из принципа наиболее благоприятствуемой нации, применяются только при наличии достаточного повода, оправдывающего их использование. Антидемпинговые меры разрешены правом ВТО в первую очередь для защиты национальных производителей.

Демпинг (от англ. dumping - сброс) ввоз товаров по цене ниже нормальной стоимости, представляет собой одну из форм недобросовестной конкуренции. Демпинг может преследовать как экономическую, так и политическую цель (экономически мощная держава, осуществляя демпинг в торговле с менее развитыми странами, стремится подавить конкуренцию национальных производителей в этих странах и постепенно установить над ними экономический контроль).

Впервые законодательное закрепление антидемпинговые нормы получили в Таможенном законе Канады в 1904 году. В последующем они также были приняты в Новой Зеландии (1905 г.), Австралии (1906 г.), США (1916 г.). Следует отметить, что данные законы послужили основой для принятия в 1947 г. ст. VI ГАТT.

\section{Антидемпинговое законодательство Республики Таджикистан}

Определения понятия «демпинг» в антидемпинговом законодательстве членов ВТО во многом схожи. В Законе РТ «О внешнеторговой деятельности» от 3 июля 2012 г. № 846 он определяется как импорт товаров в PT по цене ниже себестоимости, повлекший причинение материального ущерба или угрозу причинения такого ущерба промышленности, созданной в РТ, или существенно замедляющий создание промышленности в РТ [4]. В Законе Республики Казахстан «Об антидем- 
пинговых мерах» от 13 июля 1999 г. № 421-I под демпингом понимаются поставки на территорию Республики Казахстан товара, реализуемого по цене ниже его нормальной стоимости. В Законе Республики Кыргызстан «Об антидемпинге» от 31 октября 1998 г. № 139 демпинг (ввоз демпингового товара) определяется как недобросовестные действия поставщика по ввозу на таможенную территорию Кыргызской Республики для свободного обращения товара по цене ниже его нормальной стоимости.

Следует подчеркнуть, что демпинг как таковой не запрещается, а осуждается лишь такой демпинг, который имеет своим следствием определенный материальный ущерб [8].

С момента подачи в июне 2001 г. заявки на вступление в ВТО Республика Таджикистан начала поэтапно адаптировать свое законодательство к требованиям права ВТО и непосредственно антидемпингового процесса в Таджикистане. Роль права ВТО в развитии национального законодательства и всего международного антидемпингового права неоценима. После принятия Антидемпингового кодекса 1979 г. в рамках ГАТТ-47 и Соглашения о применении ст. VI ГАТT-94 проблематика применения антидемпинговых мер вынесена на универсальный уровень [2, с. 8].

В ходе работы Уругвайского раунда в связи с развитием рынка и предотвращением произвольного использования национального антидемпингового законодательства был поднят вопрос о пересмотре Антидемпингового кодекса 1979 года. Результатом данных переговоров стало принятие Соглашения о применении ст. VI ГАТТ (Антидемпинговый кодекс 1994 г.) [7].

Антидемпинговое законодательство Республики Таджикистан сформировалось за весьма короткий промежуток времени под значительным влиянием права ВТО и во многом благодаря такому влиянию. На основе права ВТО Республика Таджикистан приняла собственный нормативный правовой акт в сфере использования антидемпинга, компенсационных пошлин и защитных мер.

Правовая основа для дополнительных защитных мер в Республике Таджикистан обеспечивалась Законом РТ «О таможенных тарифах» 1999 г., однако он был отменен.
В свою очередь ст. 344 Таможенного кодекса РТ 2004 г. предусматривала общую структуру применения антидемпинговых, компенсационных пошлин и защитных мер. В частности, в ст. 344 подчеркивалось, что особые таможенные пошлины (специальные, антидемпинговые и компенсационные) могут временно применяться к ввозимым товарам в соответствии с законодательством РТ о внешнеторговой деятельности и международными правовыми актами, признанными Таджикистаном. После принятия нового закона «О внешнеторговой деятельности» от 3 июля 2012 г. № 846 положения данной статьи утратили свою силу.

Основная цель принятия указанного закона состояла в приведении законодательства Таджикистана в области антидемпинговых, компенсационных и защитных мер в соответствие с правом ВТО. В нем подчеркивается приоритет международного права над национальным антимонопольным законодательством ${ }^{1}$. Данный закон был принят после проведения 7-го заседания рабочей группы по вступлению РТ в ВТО. Следует отметить, что таким образом впервые в законодательстве РТ был более подробно регламентирован порядок применения антидемпинговых и компенсационных пошлин, в частности:

- значительного увеличения демпингового или субсидируемого импорта по отношению к внутреннему производству или потреблению;

- значительного ценового занижения со стороны демпингового или субсидируемого импорта по отношению к цене подобной отечественной продукции или значительного снижения цен на аналогичный товар в связи с таким импортом, или предотвращения роста цен, который в результате нанес бы материальный ущерб отечественной промышленности, или имелась угроза такого ущерба для отечественной промышленности.

Согласно данному закону антидемпинговая пошлина не превышает суммы, необходимой для устранения ущерба отечественной промышленности, или суммы, равной по размеру полной демпинговой марже, то есть разнице между нормальной стоимостью товаров и ценой на такие товары, когда они предназначены для экспорта в Таджикистан. Компен- 


\section{МЕЖДУНАРОДНОЕ ПРАВО И СРАВНИТЕЛЬНОЕ ПРАВОВЕДЕНИЕ}

сационная пошлина не должна превышать суммы, необходимой для устранения ущерба отечественной промышленности, или полной суммы субсидии.

Особое внимание в этом законе уделено порядку и процедуре проведения расследования. В нем определено, что антидемпинговые и компенсационные пошлины будут применяться в результате расследования компетентными органами, отвечающими за выявление демпинга или субсидирования, материального ущерба и причинно-следственной связи. Законом предоставлена возможность представительским организациям потребителей принимать участие в расследовании и защищать свои интересы. Расследование длится в течение одного года и может быть продлено в случае необходимости, но в общей сложности не более 18 месяцев с момента начала расследования.

Согласно данному закону в случае необходимости правительство может использовать временные меры по истечении 60 дней с начала расследования. Временные меры могут быть применены в следующих случаях:

- вероятен демпинг и/или субсидирование и нанесение ущерба отечественной промышленности;

- задержка может привести к ущербу, который будет трудно возместить;

- заинтересованным сторонам была дана возможность представить информацию, необходимую для защиты своих интересов.

В законе также предусмотрен период, на который антидемпинговые или компенсационные пошлины будут оставаться в силе, а именно на период, необходимый для устранения ущерба, но не более пяти лет с момента введения или последнего пересмотра. Данные пошлины будут отменены, если проверка покажет, что из-за их прекращения демпинг, субсидии или причины ущерба отечественной промышленности вряд ли продолжатся или повторятся.

Антидемпинговые кодексы 1979 и 1994 гг. закрепляют общий принцип, согласно которому антидемпинговые меры должны оставаться в силе только то время, которое необходимо для противодействия причиняющему ущерб демпингу [1, с. 96].

Следует отметить, что в данном законе не предусмотрено положение, касающееся об- ратной силы, в случае окончательного определения наличия ущерба, когда влияние демпингового импорта в отсутствие временных мер привело бы к определению наличия ущерба и когда антидемпинговые пошлины могут взиматься с учетом положения об обратной силе за период, в течение которого применялись временные меры, если таковые вводились. В случае принятия ценового обязательства расследование в отношении наличия демпинга и ущерба продолжается, если этого требует экспортер или компетентный орган [9].

\section{Применение защитных мер членами ВТО}

Закон предусматривает возможность применения защитных мер. Их суть состоит в том, что страна, включившая в свое законодательство или международное соглашение защитную оговорку, получает возможность, не нарушая соглашения и не отказываясь от своих обязательств, отменить ранее предоставленную тарифную уступку или ввести дополнительное ограничение ввоза как временную чрезвычайную меру в том случае, если импорт иностранных товаров возрастет по непредвиденным обстоятельствам в такой степени, что будет причинять серьезный ущерб национальному производству [3, с. 353].

В законе установлено, что защитные меры могут быть использованы в случае возникновения необходимости устранения ущерба отечественной промышленности в связи с ростом импорта при условии того, что конкретный продукт импортировался в течение определенного периода в возросшем объеме в абсолютных и относительных показателях по отношению к внутреннему производству на условиях, которые создали предпосылки или угрозу нанесения серьезного ущерба отечественной промышленности, производящей аналогичную или непосредственно конкурирующую продукцию. Защитные меры могут применяться после проведения расследования и на основе его результатов. Решение о начале расследования будет публиковаться и доводиться до сведения всех заинтересованных сторон.

Следует подчеркнуть, что защитные меры активно используются членами ВТО. 
Только в течение 2000 г. Комитет по защитным мерам рассмотрел 40 извещений о начале расследований с целью введения защитных мер и получил 25 извещений о введении защитных мер и 15 извещений о введении временных мер. Данное обстоятельство свидетельствует о том, что данный механизм работает в рамках ВТО [3, с. 359].

В Законе определено, что защитные меры могут приниматься в форме повышения тарифа либо количественных ограничений, будут использованы для устранения серьезного ущерба и облегчения корректировки и оставаться в силе, пока это необходимо для устранения ущерба, но не более четырех лет с момента их введения. Предварительная защитная мера в форме повышения тарифов может быть введена на срок не более 200 дней, если имеются четкие доказательства того, что увеличение импорта привело или угрожает нанести серьезный ущерб национальной производственной отрасли и любая задержка во введении защитных мер может привести к ущербу, который будет трудно восстановить.

На сегодняшний день антидемпинговое регулирование позволяет показательно раскрыть различные аспекты и направления государственного регулирования внешней торговли членов ВТО, прежде всего антидемпинговой политики.

В настоящее время в законодательстве Таджикистана в области антидемпинга, компенсационных пошлин и защитных мер требуется принятие специального закона, посвященного антидемпинговому законодательству. В данном законе должны быть рассмотрены вопросы регулирования технических и процедурных аспектов расследования, а также определены единые механизмы применения защитных, антидемпинговых и компенсационных мер, соответствующие праву ВТО.

\section{Выводы}

Таджикистан в отчете рабочей группы по вступлению РТ в ВТО взял на себя обязательства, что не будет применять никаких антидемпинговых, компенсационных пошлин или защитных мер до принятия детальных подзаконных актов к закону «О внешнеторговой деятельности» и что после вступления он бу- дет уведомлять и предоставлять копии законодательных актов, применимых в этих областях, включая любые подзаконные акты, в соответствующие комитеты ВТО. Из этого можно смело сделать вывод, что право ВТО и в будущем будет позитивно влиять как на совершенствование антидемпингового законодательства, так и правовой системы Республики Таджикистан в целом.

\section{ПРИМЕЧАНИЕ}

${ }^{1}$ В статье 4 данного Закона закреплено, что если международным правовым актом, признанным Таджикистаном, установлены иные нормы, чем те, которые содержатся в настоящем Законе, то применяются нормы международного правового акта.

\section{СПИСОК ЛИТЕРАТУРЫ}

1. Воробьева, Н. Г. Международные соглашения Всемирной торговой организации о мерах по защите экономических интересов государств : дис. ... канд. юрид. наук / Воробьева Наталья Григорьевна. - М., 2000. - 159 c.

2. Галичий, С. А. Соотношение международно-правового и внутригосударственного регулирования антидемпингового процесса в Российской Федерации и государствах-членах ВТО : дис. ... канд. юрид. наук / Галичий Сергей Александрович. - М., 2008. $-159 \mathrm{c}$.

3. Дюмулен, И. И. Международная торговля. Тарифное и нетарифное регулирование / И. И. Дюмулен. - М. : ВАВТ, 2015. - 548 c.

4. Закон Республики Таджикистан «О внешнеторговой деятельности» от 3 июля 2012 г. № 846. Электрон. текстовые дан. - Режим доступа: http:// mmk.tj/ru/legislation/legislation-base/. - Загл. с экрана.

5. Мансуров, У. А. Сотрудничество Республики Таджикистан с межправительственными организациями универсального характера (международно-правовой аспект) / У. А. Мансуров. - Душанбе, 2010. - $137 \mathrm{c}$.

6. Мещерякова, О. М. Проблематика взаимоотношений России - ЕС после вступления России в ВТО / О. М. Мещерякова // Вестник Волгоградского государственного университета. Серия 5, Юриспруденция. -2013. - № 1 (18). - С. 85-87.

7. Соглашение по применению статьи VI Генерального соглашения по тарифам и торговле 1994 года (ВТО, Уругвайский раунд многосторонних торговых переговоров, 15 апреля 1994 г.). - Элек- 


\section{МЕЖДУНАРОДНОЕ ПРАВО И СРАВНИТЕЛЬНОЕ ПРАВОВЕДЕНИЕ}

трон. текстовые дан. - Режим доступа: http://www. wto.ru. - Загл. с экрана.

8. Шепенко, Р. А. Введение в право ВТО: курс антидемпингового регулирования / Р. А. Шепенко. М. : Проспект, 2014. - 216 с.

9. Шумилов, В. М. Международное экономическое право / В. М. Шумилов. - М. : Юрайт, 2004. $612 \mathrm{c}$

\section{REFERENCES}

1. Vorobyeva N.G. Mezhdunarodnye soglasheniya Vsemirnoy torgovoy organizatsii o merakh po zashchite ekonomicheskikh interesov gosudarstv: dis. ... kand. yurid. nauk [International Agreements of the World Trade Organization on the Measures for Protection of States' Economic Interests. Cand. jurid. sci. diss.]. Moscow, 2000. 159 p.

2. Galichiy S.A. Sootnoshenie mezhdunarodnopravovogo i vnutrigosudarstvennogo regulirovaniya antidempingovogo protsessa $v$ Rossiyskoy Federatsii i gosudarstvakh-chlenakh VTO: dis. ... kand. yurid. nauk [The Ratio of International Legal Regulation and Intrastate Regulation of the Anti-Dumping Process in Russia and the WTO Member States. Cand. jurid. sci. diss.]. Moscow, 2008. 159 p.

3. Dyumulen I.I. Mezhdunarodnaya torgovlya. Tarifnoe $i$ netarifnoe regulirovanie [International Trade. Tariff and Nontariff Regulation]. Moscow, RFTA Publ., 2015. 548 p.

4. Zakon Respubliki Tadzhikistan «O vneshnetorgovoy deyatelnosti» ot 3 iyulya 2012 g. № 846
[The Law of the Republic of Tajikistan "On Foreign Trade Activity” of July 3, 2012 no. 846]. URL: http:// mmk.tj/ru/legislation/legislation-base/.

5. Mansurov U.A. Sotrudnichestvo Respubliki Tadzhikistan s mezhpravitelstvennymi organizatsiyami universalnogo kharaktera (mezhdunarodno-pravovoy aspekt) [Cooperation of the Republic of Tajikistan with the Intergovernmental Organizations of Universal Nature (International Legal Aspects)]. Dushanbe, 2010. 137 p.

6. Meshcheryakova O.M. Problematika vzaimootnosheniy Rossii - ES posle vstupleniya Rossii v VTO [The Issue of Relations between Russia and the EU after Russia's WTO Accession]. Vestnik Volgogradskogo gosudarstvennogo universiteta. Seriya 5, Yurisprudentsiya [Science Journal of Volgograd State University. Jurisprudence], 2013, no. 1 (18), pp. 85-87.

7. Soglashenie po primeneniyu statyi VI Generalnogo soglasheniya po tarifam i torgovle 1994 goda (VTO, Urugvayskiy raund mnogostoronnikh torgovykh peregovorov, 15 aprelya 1994 g.) [Agreement on Implementation of Article VI of the General Agreement on Tariffs and Trade 1994 (the WTO, the Uruguay Round of Multilateral Trade Negotiations, April 15, 1994)]. URL: http://www. wto.ru.

8. Shepenko R.A. Vvedenie v pravo VTO: kurs antidempingovogo regulirovaniya [Introduction to the Law ofWTO: Anti-Dumping Regulation Course]. Moscow, Prospekt Publ., 2014. 216 p.

9. Shumilov V.M. Mezhdunarodnoe ekonomicheskoe pravo [International Economic Law]. Moscow, Yurayt Publ., 2004. 612 p.

\section{Information about the Authors}

Andrey M. Nikolaev, Doctor of Juridical Sciences, Professor, Department of International Law, RUDN University, Miklukho-Maklaya St., 6, 117198 Moscow, Russian Federation, dr.andrey.nikolaev@yandex.ru.

Umed M. Mamadamonov, Senior Lecturer, Department of International Law and Comparative Law, Russian-Tajik (Slavic) University, Mirzo Tursunzade St., 30, 734000 Dushanbe, Tajikistan, mumed@yandex.ru.

\section{Информация об авторах}

Андрей Михайлович Николаев, доктор юридических наук, профессор кафедры международного права, Российский университет дружбы народов, ул. Миклухо-Маклая, 6, 117198 г. Москва, Российская Федерация, dr.andrey.nikolaev@yandex.ru.

Умед Мулкамонович Мамадамонов, старший преподаватель кафедры международного права и сравнительного правоведения, Российско-Таджикский (славянский) университет, ул. Мирзо Турсунзаде, 30, 734000 г. Душанбе, Республика Таджикистан, mumed@yandex.ru. 